\title{
Approach to cytomegalovirus infections in patients with ulcerative colitis
}

\author{
Sung Chul Park ${ }^{1}$, Yoon Mi Jeen ${ }^{2}$, and Yoon Tae Jeen ${ }^{3}$
}

\author{
${ }^{1}$ Department of Internal Medicine, \\ Kangwon National University \\ Hospital, Chuncheon; ${ }^{2}$ Department \\ of Pathology, Soon Chun Hyang \\ University Seoul Hospital, Seoul; \\ ${ }^{3}$ Department of Internal Medicine, \\ Korea University Anam Hospital, \\ Seoul, Korea

\section{Received: February 9, 2017 Accepted: March 6, 2017}

\section{Correspondence to \\ Yoon Mi Jeen, M.D.} \\ Department of Pathology, Soon \\ Chun Hyang University Seoul \\ Hospital, 59 Daesagwan-ro, \\ Yongsan-gu, Seoul 04401, Korea \\ Tel: +82-2-709-9435 \\ Fax: +82-2-709-9441 \\ E-mail:jeeny109@schmc.ac.kr
}

Cytomegalovirus (CMV) reactivation is common in patients with severe ulcerative colitis (UC), and may reflect exacerbation of mucosal inflammation and/or administration of immunosuppressants. The question of whether CMV is an active pathogen or 'an innocent bystander' in the exacerbation of UC remains controversial. Patients with UC exacerbated by reactivated CMV experience worse prognoses than those without CMV reactivation and antiviral therapy significantly reduces the need for colectomy in patients with severe UC and high-grade CMV infection, indicating that CMV plays a role in UC prognosis. Therefore, the CMV status of patients on immunosuppressants, particularly those with steroid-refractory or -dependent UC, should be tested. When CMV is detected, be performed based on should adequate treatment the extent of the viral load and the presence of certain clinical features including a large ulcer. Anti-tumor necrosis factor agents may be useful for treating CMV colitis complicating UC.

Keywords: Cytomegalovirus; Colitis, ulcerative

\section{INTRODUCTION}

Cytomegalovirus (CMV) is a double-stranded DNA virus of the family Herpesviridae. Humans are the only natural hosts of CMV, and infections are common; the seroprevalence ranges from $45 \%$ to $100 \%$. CMV is more common in Asia, South America, and Africa than in Western Europe or the United States [1].

CMV lesions may be caused by primary infection or reactivation of latent virus, or may develop when a seropositive patient is reinfected via transplantation or blood transfusion. Most primary infections are asymptomatic in immunocompetent patients. Many subjects are exposed to CMV via inapparent infections during early childhood. After initial infection, CMV resides latently in monocytes, fibroblasts, myeloid cells, and endothelial cells; lesions develop upon reactivation by proinflammatory cytokines such as tumor necrosis fac- tor $\alpha(\mathrm{TNF}-\alpha)$ and catecholamine. CMV reactivation in patients of compromised immune status (such as organ transplant recipients or those with acquired immunodeficiency syndrome [AIDS]), can cause severe complications, including pneumonia, retinitis, and colitis. CMV lesions are evident throughout the gastrointestinal tract; thus, from the oral cavity to the rectum. However, colon involvement is most commonly reported [2]. CMV colitis is very rare in immunocompetent patients. The first case of CMV colitis associated with ulcerative colitis (UC) was reported 50 years ago [3]. In UC patients, mucosal inflammation often becomes exacerbated and immunomodulatory steroids are commonly given to treat such flare-ups. Such treatment may induce CMV colitis. However, any role for CMV in exacerbation of inflammatory bowel disease (IBD) remains unclear. Furthermore, the treatment of patients with both a CMV infection and UC remains very controversial. Should 
treatment seek to eliminate CMV infection or treat the UC, or should both conditions be aggressively treated? Herein, we discuss the diagnosis and treatment of CMV infection in UC patients.

\section{THE ROLE PLAYED BY CMV INFECTION IN IBD}

The prevalence of CMV infection in IBD patients is unclear; most studies examined only selected patients and used different methods to diagnose CMV infection; selection bias was in play. The prevalence of CMV infection in patients with moderate-to-severe UC ranged from $16 \%$ to $34 \%$ when various diagnostic methods (serological and histological tests) were employed $[4,5]$. The CMV infection rate in those with severely steroid-refractory UC ranged from $20 \%$ to $40 \%$ when infection was diagnosed using a combination of antigenemia and histological evaluations (H\&E staining and immunohistochemistry [IHC]) [6-9]. Recently, a multicenter, prospective Korean study detected CMV infections in $43 \%$ and $67 \%$ of patients with moderate-to-severe active and steroid-refractory UC, respectively, based on both serological testing (immunoglobulin $\mathrm{M}$ [IgM] antibody levels) and histological criteria including IHC staining and polymerase chain reaction (PCR) [10].

UC patients become CMV-infected at a markedly higher rate than do Crohn disease (CD) patients [11]. Most CD patients are negative for CMV upon IHC staining, and CMV was very rarely detected ( $<5 \%$ of patients) via PCR of biopsy and fecal specimens [12]. TNF- $\alpha$ plays an important role in CMV reactivation within monocytes and dendritic cells; interferon $\gamma($ IFN- $\gamma$ ) secreted by CD4+ T cells inhibits CMV reactivation [13]. CD is an inflammatory disease involving; $\mathrm{T}$ helper (Th) 1 and Th17 cells with high expression of the antiviral cytokine IFN- $\gamma$. UC is a Th2-type inflammatory process with downregulation of these cytokines. CMV reactivation is thus rare in CD patients, but not uncommon in UC patients.

Carrying CMV does not necessarily imply that CMVmediated disease is present [14]. CMV infection implies that CMV is detectable in blood or biopsy specimens either serologically or via viral DNA analysis; CMV disease includes only conditions characterized by clinical symptoms and end-organ damage attributable to the virus. In other words, CMV disease is associated with clinical features such as fever, leukopenia, hemaphagocytosis, meningoencephalitis, pneumonitis, colitis, and hepatitis. CMV disease involving the gut is termed CMV colitis [14-16].

The question of whether CMV is an active pathogen or 'an innocent bystander' in IBD patients remains controversial. Recent studies have suggested that CMV may exacerbate the course of UC. CMV infection increased the risk of hospitalization attributable to UC exacerbation 8.2-fold, and patients with histories of CMV colitis within the 3 months prior to commencement of infliximab therapy were 6.47-fold more likely not to respond to such therapy $[17,18]$. Kim et al. [19] studied a cohort of 72 patients with moderate-to-severe UC assessed in terms of CMV reactivation at the times of early UC flares; the CMV-positive group required a significantly higher number of cumulative colectomies (log-rank $p=0.025$ ) and exhibited a greater disease flare-up rate (log-rank $p$ $=0.048)$. However, another study found that CMV reactivation in patients with moderate-to-severe UC did not significantly affect the proportions of patients entering remission or requiring colectomies [20]. However, in the cited study, the CMV reactivation group contained a significantly higher proportion of patients who underwent early rescue therapy using cyclosporin A; this may have influenced the results [20]. Another study using PCR to detect CMV DNA in the inflamed colonic mucosa of patients with immunosuppressant-refractory UC found that the colectomy rate was higher in CMV DNA-positive $(29.4 \%)$ than -negative patients (7.7\%). However, the difference was not statistically significant because the sample size was small $(\mathrm{n}=30)$ [21]. Therefore, CMV infection may be poorly prognostic of the course of UC.

\section{DIAGNOSIS OF CMV COLITIS}

\section{When should UC complicated by CMV infection be suspected?}

Although patients with UC may require early diagnosis and appropriate treatment of CMV infection, CMV may become sporadically reactivated in such patients and then disappear even without prescription of antiviral agents. Matsuoka et al. [20] assayed CMV levels at 2-week intervals for 8 weeks in 69 patients with severe UC to assess CMV reactivation. Such reactivation was di- 

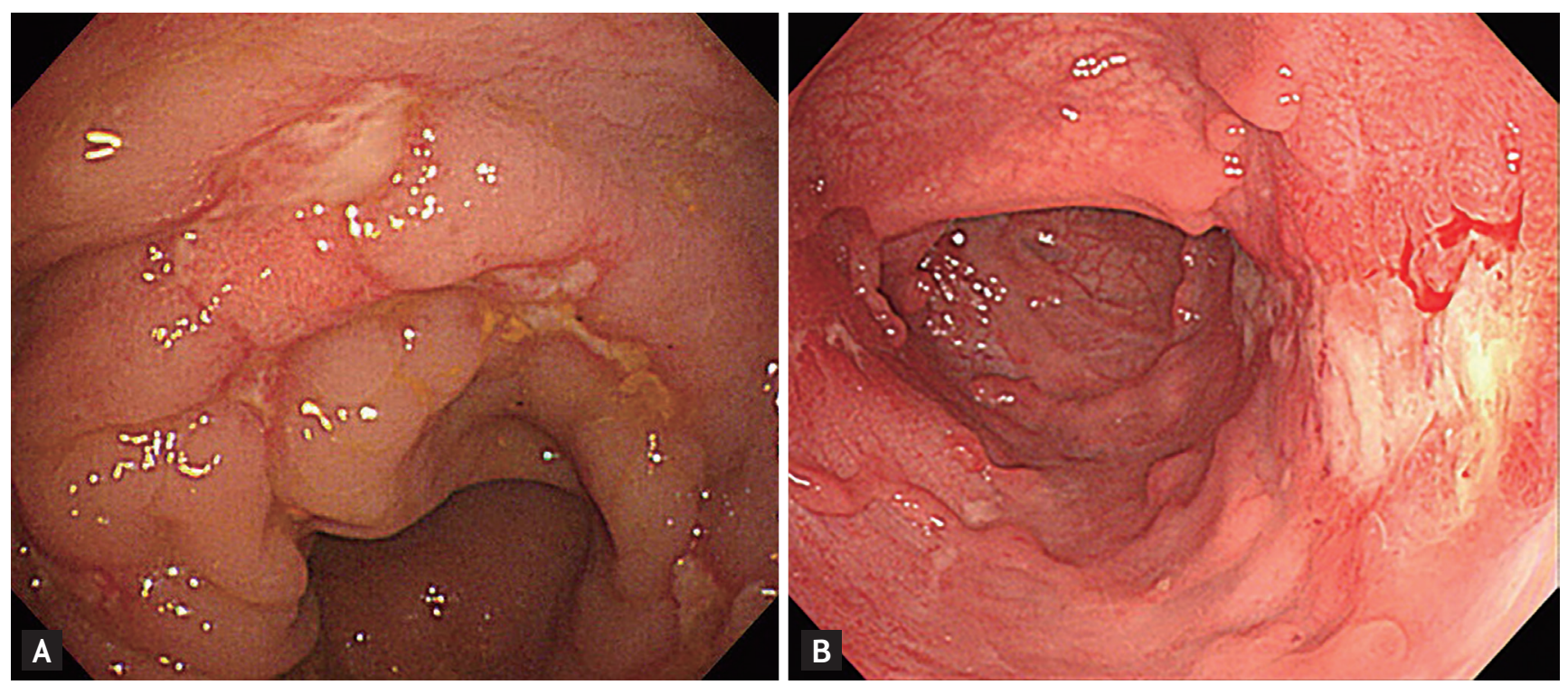

Figure 1. (A, B) Endoscopic findings in patients with cytomegalovirus colitis.

agnosed by CMV antigenemia (one or more virus-positive cells) or CMV PCR ( $\geq 20$ copies of CMV DNA/100 $\mu \mathrm{L}$ of plasma). Forty-eight patients $(69.6 \%)$ were positive for CMV IgG, and half $(25 / 48,52.1 \%)$ showed evidence of CMV reactivation. No significant difference in the rate of either remission or colectomy was evident between the CMV reactivation and the other group; reactivation resolved without antiviral therapy in most patients. do Carmo et al. [22] found that it was rare ( $<5 \%$ of cases) for patients with IBD to develop an active CMV infection (CMV IgM-positivity or CMV DNA detected via qualitative or quantitative PCR in peripheral blood or a fecal specimen). Therefore, blood tests exploring CMV infection status need not be performed in all IBD patients.

Recently reported risk factors for CMV disease in IBD patients include age $>30$ years, immunomodulatory treatment, and refractoriness to drugs such as corticosteroids or TNF antagonists [23]. Another study found that a leukocyte count $<11,000 / \mathrm{mL}$ and a disease duration $<60$ months were risk factors for CMV infection, in addition to age $\geq 30$ years and immunosuppressant use [24]. Thus, CMV infection status should be determined in older UC patients who are refractory to immunomodulators such as high-dose steroids, or whose symptoms persist or deteriorate as the steroid dose is reduced.

\section{Symptoms and signs of CMV colitis}

CMV colitis should be suspected in UC patients with se- vere clinical symptoms. However, it is difficult to distinguish UC exacerbation from CMV colitis by reference to symptoms only. CMV colitis may be accompanied by diarrhea, bloody stool, crampy abdominal pain, rectal urgency, and tenesmus, as well as systemic conditions such as fever, fatigue, and weight loss. C-reactive protein levels increase abruptly in some patients with CMV colitis. Furthermore, such colitis can cause complications such as severe hemorrhage, a megacolon, fulminant colitis, and colon perforation [25]. Endoscopic findings in patients with CMV colitis include punched-out, geographic, longitudinal, and irregular ulcers; erythema; exudate; erosion; diffuse mucosal edema; and pseudotumoral lesions (Fig. 1) [26,27]. One study found that irregular ulceration and wide mucosal defects were more common in patients with UC complicated by CMV infection than in those with UC alone. However, CMV may be detected even if ulcers are absent; it is difficult to differentiate CMV colitis from acute exacerbation of severe UC based only on endoscopic findings [27]. Therefore, to ensure early diagnosis, CMV colitis should be suspected in all patients who do not improve on steroids or immunomodulatory therapy.

\section{Diagnostic tests for CMV colitis}

Diagnostic blood tests for CMV include serum antibody measurements, the CMV antigenemia assay, and PCR of CMV DNA (Table 1). Blood tests are non-invasive and 
simple. A positive CMV IgG antibody test confirms past exposure to CMV and identifies patients at risk of CMV colitis; the test is highly sensitive and specific when used to detect latent infections. Although the CMV IgM antibody test is very sensitive and specific when employed to detect acute infection or CMV reactivation accompanied by viremia, the results do not correlate well with CMV colitis [14]. The CMV antigenemia assay semi-quantitatively detects the pp65 antigen in polymorphonuclear leucocytes (PMNs) of peripheral blood. CMV antigen-positive PMNs develop when antigens produced by CMV-infected cells are absorbed by the nuclei of PMNs, indicating systemic CMV reactivation. CMV antigenemia assay positivity is defined as at least one pp65-positive cell per $2 \times 10^{5}$ PMNs. However, antigenemia assay results may depend on disease severity and the doses of immunosuppressants (such as steroids) prescribed; no cut-off value for diagnosis of CMV colitis has yet been established. PCR of serum CMV DNA may be diagnostic, but no cut-off value separating latent from active infection has yet been defined. PCR of serum is more useful for detection of CMV viremia than is detection of anti-CMV antibodies; the latter tests lack clinical utility. Both the CMV antigenemia assay and PCR of blood DNA are of limited value in UC patients because such patients have lower levels of CMV than do transplant recipients. In a recent study diagnosing suspected CMV colitis in patients with moderate-to-severe UC, serum DNA PCR-positivity was defined as $>250$ copies $/ \mathrm{mL}$. The sensitivities of the CMV antigenemia and serum CMV DNA PCR tests were relatively low (47.0\% and $44.3 \%$, respectively); however, the specificities were high (81.7\% and 87.9\%) [28]. Notably, both the CMV antigenemia and blood CMV DNA PCR tests were diagnostically useful in UC patients with endoscopically significant ulcers; the tests predicted CMV colitis with $67.3 \%$ sensitivity and 75.7\% specificity in such patients. Furthermore, CMV antigenemia-positivity was significantly associated with the need for subsequent colectomy in patients with UC and CMV colitis, suggesting that the test usefully predicted the clinical course of the disease. Similarly, Chun et al. [29] found that, in patients with moderate-to-se-

Table 1. Characteristics of diagnostic tests for CMV colitis

\begin{tabular}{|c|c|c|}
\hline Diagnostic test & Pros & Cons \\
\hline CMV IgG & $\begin{array}{l}\text { Verifies prior exposure to CMV } \\
\text { Distinguishes patients with risk for CMV colitis }\end{array}$ & Uncorrelated with CMV colitis \\
\hline CMV IgM & $\begin{array}{l}\text { Verifies acute infection or reactivation } \\
\text { accompanied by viremia }\end{array}$ & Presents systemic disease \\
\hline Antigenemia assay & $\begin{array}{l}\text { Relatively high specificity for the diagnosis } \\
\text { of CMV colitis } \\
\text { Takes a short time to obtain results ( } 24 \text { hour) } \\
\text { Helpful for predicting clinical course of CMV } \\
\text { colitis }\end{array}$ & $\begin{array}{l}\text { Relatively low sensitivity for the diagnosis of } \\
\text { CMV colitis }\end{array}$ \\
\hline Blood CMV DNA PCR & Noninvasive; endoscopy is not required & $\begin{array}{l}\text { Requires a cut-off value for the diagnosis of } \\
\text { CMV colitis }\end{array}$ \\
\hline $\begin{array}{l}\text { Histological H\&E } \\
\text { staining }\end{array}$ & High specificity for the diagnosis of CMV colitis & $\begin{array}{l}\text { Low sensitivity for CMV colitis } \\
\text { Requires many tissue samples and skilled } \\
\text { pathologist }\end{array}$ \\
\hline $\begin{array}{l}\text { Histological IHC } \\
\text { staining }\end{array}$ & $\begin{array}{l}\text { Higher sensitivity than H\&E for the diagnosis } \\
\text { of CMV colitis }\end{array}$ & Takes a long time to obtain results (3-5 days) \\
\hline Tissue CMV DNA PCR & Very high sensitivity for CMV detection in colon & Clinical meaning of positivity is unclear \\
\hline Endoscopy & High sensitivity for the diagnosis of CMV colitis & Low specificity for the diagnosis of CMV colitis \\
\hline Culture & $\begin{array}{l}\text { High sensitivity and specificity for the diagnosis } \\
\text { of CMV colitis }\end{array}$ & Takes a long time to obtain results (2-4 weeks) \\
\hline
\end{tabular}

CMV, cytomegalovirus; IgG, immunoglobulin G; IgM, immunoglobulin M; PCR, polymerase chain reaction; IHC, immunohistochemistry. 
vere UC, the CMV antigenemia assay exhibited relatively low sensitivity (66.7\%) but high specificity (87.1\%) when used to diagnose CMV colitis; antigenemia-positivity was significantly associated with refractoriness to corticosteroid therapy. The receiver operating characteristic curve showed that the optimal cut-off value was two pp65-positive cells, affording a sensitivity of $66.7 \%$ and a specificity of $90.3 \%$. These findings suggest that although the low sensitivity of the CMV antigenemia assay renders it difficult to replace endoscopic biopsy with the assay when it is sought to diagnose CMV colitis in patients with UC, the high diagnostic specificity might aid in early diagnosis of CMV colitis in severely ill patients who require prompt treatment prior to time-consuming IHC staining. Furthermore, as CMV infection is associated with poor responses to steroids and infliximab, use of the CMV antigenemia assay prior to the administration of such drugs in the acute exacerbation phase of UC might usefully predict the drug response. Early rescue therapy might be appropriate for UC patients who are positive on the CMV antigenemia assay [30].

Active CMV colitis is usually diagnosed by endoscopic CMV detection in colonic tissue, histological tests including H\&E and IHC staining, and/or tissue PCR. H\&E staining reveals the classical "owl's eye" feature; the nuclei of cytomegalic cells containing CMV inclusion bodies are surrounded by clear cytoplasm. This diagnostic method affords high specificity (92\% to $100 \%$ ), but low and variable sensitivity (10\% to $87 \%$ ); a combination of $\mathrm{H} \& \mathrm{E}$ and IHC staining increases the sensitivity to $78 \%$ to $93 \%[31,32]$.

PCR of CMV DNA in colonic tissue exhibits high sensitivity (92\% to $96.7 \%$ ) and specificity (93\% to $98.7 \%$ ) when used to diagnose CMV infection [33,34]. Therefore, PCR of a colonic mucosal specimen may be helpful in IHC-negative cases of suspected CMV infection. However, the clinical significance of a positive PCR result is unclear in the absence of histological signs of CMV colitis; the presence of CMV DNA alone does not distinguish a latent from an active infection. Quantitative PCR is also problematic; no clear criteria differentiating between a simple CMV infection and CMV disease are yet available. One study found that $\geq 250$ copies of CMV DNA/mg of colonic tissue, calculated via quantitative PCR, predicted the resistance of patients with active
UC to continuous intravenous (IV) steroids, infliximab, and cyclosporine [35]. Thus, such patients may require early antiviral therapy. Recently, Ciccocioppo et al. [36] assessed the CMV infection status of IBD patients using both IHC and quantitative real-time (RT)-PCR. A cut-off of $10^{3}$ DNA copies $/ 10^{5}$ cells of the diseased mucosa differentiated between CMV colitis and mucosal infection [36].

Specimens collected from the ulcer base and edge, and from uninvolved mucosa, were used to compare the diagnostic differences between quantitative RT-PCR and IHC staining in UC patients who underwent bowel resection [37]. No marked difference between the ulcer base and edge was evident in terms of the highest densities of CMV-positive cells. However, the uninvolved mucosa was IHC-negative for CMV and either PCR-negative for $\mathrm{CMV}$, or very low (o to 3 viral copies/mg), suggesting that the ulcer base and edge are appropriate biopsy sites. Both IHC and quantitative RT-PCR were useful for CMV detection. In terms of the adequate specimen number, one study recommended that 11 sigmoidoscopic biopsies be taken for UC diagnosis, and 16 colonoscopic biopsies for CD diagnosis [38]. However, such high numbers are associated with risks of hemorrhage and perforation. Therefore, tissue for histological examinations should be endoscopically collected at the ulcer base and edge for diagnosis of CMV colitis; the location and number of biopsies are more important than the choice of diagnostic method (IHC vs. PCR).

Despite the relatively high sensitivity ( $45 \%$ to $75 \%$ ) and specificity ( $89 \%$ to $100 \%$ ) of culture when it is sought to identify viruses, this method is of low clinical utility; no results are available for 2 to 4 weeks [39,40].

The American College of Gastroenterology guideline suggests that CMV superinfection may progress to severe colitis, refractory to maximal immunosuppressive therapy, and that diagnosis requires histological analysis employing sigmoidoscopy and viral culture [41]. The European Crohn's and Colitis Organization guideline recommends the use of antiviral therapy for acute steroid-resistant colitis when CMV is detected in colonic tissue via PCR or IHC [15]. The Korean Association for the Study of Intestinal Diseases recommends antiviral therapy for severe UC when the patient is nonresponsive to 1 to 2 weeks of IV steroid therapy and positive for CMV by endoscopy and biopsy [42]. 


\section{TREATMENT OF CMV COLITIS IN UC PATIENTS}

\section{Indications for antiviral therapy}

Antiviral therapy is not necessarily required by all patients with UC and CMV infections. Maconi et al. [43] found that antiviral treatment did not greatly influence the long-term outcomes of patients with IBD and active CMV colitis. However, in UC patients who were notably steroid-dependent or -refractory, those received antiviral treatment experienced a significantly higher clinical remission rate (77.8\%) at 12 months than did those who did not receive such treatment $(19.4 \%, p=0.038)$ [43]. A recent meta-analysis found that antiviral agents did not reduce the colectomy risk in unselected UC patients with CMV (odds ratio, 0.92; 95\% confidence interval, 0.31 to 2.76) [44]. However, antiviral therapy did significantly reduce that risk in $\mathrm{CMV}$-infected patients refractory to corticosteroids (odds ratio, 0.20; 95\% confidence interval, 0.08 to 0.49 ). Kim et al. [10] studied 31 patients with UC and CMV infections, and found that 17 whose symptoms improved when on steroids did not require antiviral therapy. However, the remaining 14 patients (who did not respond to steroid therapy) required ganciclovir [10]. Thus, antiviral therapy is required by only a subset of IBD patients.

It remains unclear whether CMV reactivation exacerbates the course of IBD. However, it is very likely that CMV is 'an innocent bystander' in patients with low CMV burdens but an active pathogen in those with high CMV burdens. One recent study classified IBD patients into a high-grade CMV density group (five or more viral inclusions evident on IHC in each biopsy specimen); a low-grade CMV density group (fewer than five inclusions); and a control group (CMV-negative). The colectomy rates for patients in the low-grade CMV density group did not vary greatly, regardless of whether antiviral therapy was prescribed (31\% and $29 \%$, respectively). However, the colectomy rates in the high-grade CMV density group differed significantly by antiviral therapy status (44\% in those on therapy and $83 \%$ in those not on therapy) [45]. Hence, CMV disease can be classified into high- and low-grade depending on the numbers of viral inclusions, suggesting that antiviral therapy should be prescribed for patients with high-grade disease, and should also be considered for those with low-grade CMV disease who are steroid-refractory or -dependent [44].
No standards allowing classification of CMV disease as high- or low-grade have yet been established, and such standards might vary depending on the CMV detection technique used. Also, no cut-off value for the CMV DNA level that should require antiviral therapy is yet available. A recent study suggested that CMV should be treated when the viral load attained $>250$ copies/mg of tissue; favorable outcomes in achieving and maintaining clinical remission were noted [35]. However, quantitative RT-PCR is often unavailable in clinical settings; often, clinicians assess CMV DNA-positivity only qualitatively. Omiya et al. [46] examined 20 patients with moderate-to-severe UC, whose colonic mucosa lacked CMV inclusion bodies, and who were negative on CMV antigenemia testing but positive on the mucosal PCR assay. The patients were divided into two groups based on the presence or absence of endoscopically visible large ulcers (> $5 \mathrm{~mm}$ ). A combination of antiviral and conventional UC therapy was prescribed for those with such ulcers; other patients received conventional UC therapy only. All 10 patients without large ulcers responded to conventional therapy. However, the patients with large ulcers responded poorly even when they were given the combined therapy; three required colectomies and four of the remaining seven developed UC flare-ups after initial remission. It was suggested that, in patients with active UC, who are CMV DNA-positive on the mucosal PCR assay, but who lack endoscopically evident large ulcers, a diagnosis of latent CMV infection is speculative and antiviral therapy is unnecessary. Therefore, antiviral therapy may be indicated for cases of steroid-refractory/-dependent UC with high-grade CMV infection as indicated by several CMV inclusions evident on IHC, and for those with > 250 CMV DNA copies/mg of tissue or low-grade CMV infection (evidenced by few inclusions or 10 to 250 DNA copies/mg of tissue) with endoscopically large ulcers (Fig. 2) [47]. However, a large-scale study is required to substantiate this suggestion.

\section{Antiviral therapies}

The remission rate of UC patients after antiviral therapy for CMV colitis is high (67\% to 100\%) [8,48,49]. Ganciclovir is the treatment of choice; the drug is usually infused intravenously because of low oral bioavailability. The recommended dose is 5 to $7.5 \mathrm{mg} / \mathrm{kg}$ twice daily for 2 to 3 weeks. As the drug is renally excreted, both the dosage 


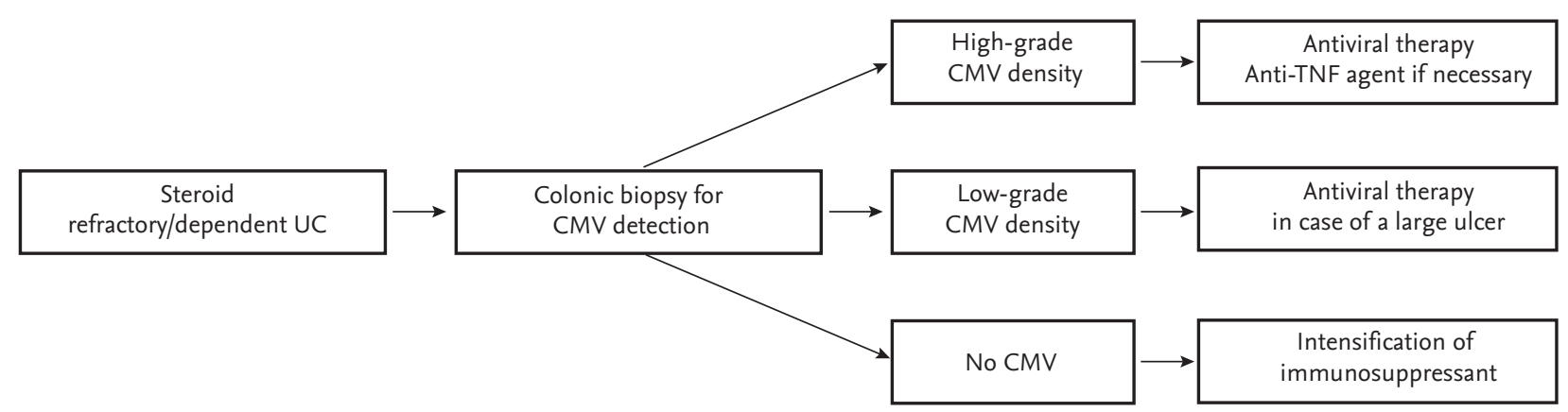

Figure 2. A management algorithm for cytomegalovirus (CMV) colitis in ulcerative colitis (UC) patients. TNF, tumor necrosis factor.

and frequency should be adjusted in patients with renal dysfunction [50]. IV antiviral therapy over 2 to 3 weeks usually requires hospitalization; however, ganciclovir may be replaced (although efficacy remains to be confirmed) with oral valganciclovir ( $1 \mathrm{~g}$ three times daily) in those treated as outpatients due to a prolonged period of antiviral therapy. Ganciclovir might induce severe complications, including myelosuppression, neutropenia, and thrombocytopenia, in addition to other abnormal reactions, such as headache, nausea, vomiting, flare, and hypotension. Hence, blood cell numbers must be monitored regularly in patients on ganciclovir. Foscarnet may serve as a secondary treatment for patients who are intolerant of, or resistant to, ganciclovir. Foscarnet is administered intravenously ( $90 \mathrm{mg} / \mathrm{kg}$ ) twice daily for 2 to 3 weeks; the principal side-effect is nephrotoxicity [15].

Follow-ups and monitoring standards after treatment of CMV colitis remain to be established. In an earlier clinical trial, blood PCR after cessation of antiviral therapy more accurately predicted the efficacy of such therapy than did viral culture or clinical assessment [51]. However, it remains unclear whether second-look endoscopy is required to confirm clearance of CMV antigens after treatment of CMV colitis.

\section{Immunomodulators in the treatment of CMV colitis}

The continued use of immunomodulators, including corticosteroids, thiopurines, and biologics, during antiviral therapy for CMV remains controversial. The European guideline recommends that cessation of all immunomodulatory therapies, including steroids, should be considered until the CMV colitis symptoms are controlled, and that no immunomodulator should be prescribed for patients with systemic CMV disease [15].
However, the evidence level for these recommendations is 5 (expert opinion). Ciccocioppo [52] suggested that steroids should be quickly tapered and discontinued, but immunosuppressants and biological agents with long-lasting effects should be maintained in patients with viral colitis (mucosal viral load $\geq 10^{3} / 10^{5}$ cells) and those exhibiting reactivation of latent infection (viral load $10^{2}$ to $10^{3}$ copies $/ 10^{5}$ cells). On the other hand, it has been suggested that any already initiated IBD treatment should be continued during antiviral therapy for CMV colitis [53]. Sager et al. [25] proposed that conventional corticosteroid therapy should be combined with antiviral therapy, and medical rescue therapy using immunosuppressants should be prescribed when necessary. Therefore, additional studies are required to explore the effects of immunomodulators employed to treat UC complicated by CMV colitis.

Currently, the effects of biologics, such as anti-TNF agents, on CMV infection remain unclear. However, it may be that anti-TNF therapy is safe in CMV colitis patients and dose not exacerbate the disease [47]. D'Ovidio et al. [54] found that, after administration of infliximab to 15 IBD patients, nine were CMV-seropositive, and CMV DNA was detected in colon specimens of three, but no subject developed CMV disease. Lavagna et al. [55] found that 42 of 60 patients (70\%) with refractory CD were CMV-seropositive; however, no patient was positive on blood CMV PCR performed during three sessions of infliximab therapy, suggesting that infliximab did not reactivate CMV. In a recent study, flare-ups in UC patients on maintenance therapy with azathioprine, or anti-TNF therapies such as infliximab and adalimumab, were evaluated. The proportions of patients exhibiting CMV reactivation at flare-up did not differ between the 
anti-TNF (35\%) and the azathioprine group (38\%), and the CMV DNA load did not become elevated during anti-TNF therapy. Furthermore, when the infliximab doses were increased from 5 to $10 \mathrm{mg} / \mathrm{kg}$ after flare-ups in patients on anti-TNF therapy, the clinical responses did not differ in terms of CMV reactivation [56]. Anti-TNF agents inhibit CMV reactivation and reduce the incidence of CMV colitis by lowering TNF- $\alpha$ levels in colon tissue. Therefore, anti-TNF therapy may be preferable to other immunosuppressant therapies used to treat CMV reactivation-associated flare-ups in UC patients.

Several studies have shown that ganciclovir is essential for patients with steroid-refractory or -dependent UC and histologically high-grade CMV infections. Concomitant anti-TNF therapy to treat the UC may also be appropriate (Fig. 2) [14,47].

\section{CONCLUSIONS}

CMV reactivation is more common in patients with severe UC than severe CD, and in Asia than in the West. As reactivation is triggered by clinical stimuli, including the use of immunosuppressants and exacerbation of mucosal inflammation, CMV screening is required only for a subset of patients with UC CMV colitis can be diagnosed by histological IHC staining and tissue PCR; blood tests such as the CMV antigenemia assay may aid in early diagnosis and predict the clinical course. Prescription of antiviral therapy may be based on the colon viral load. However, when such assessment is practically difficult, an endoscopically large ulcer may indicate that therapy is required. Anti-TNF therapy as a step-up therapy may be considered to treat CMV reactivation-associated flare-ups in UC patients, in combination with antiviral treatment. However, a large-scale study is required to explore the utility of immunomodulators as treatments for CMV colitis complicating UC.

\section{Conflict of interest}

No potential conflict of interest relevant to this article was reported.

\section{REFERENCES}

1. Cannon MJ, Schmid DS, Hyde TB. Review of cytomegalovirus seroprevalence and demographic characteristics associated with infection. Rev Med Virol 2010;20:202-213.

2. Rowshani AT, Bemelman FJ, van Leeuwen EM, van Lier RA, ten Berge IJ. Clinical and immunologic aspects of cytomegalovirus infection in solid organ transplant recipients. Transplantation 2005;79:381-386.

3. Powell RD, Warner NE, Levine RS, Kirsner JB. Cytomegalic inclusion disease and ulcerative colitis: report of a case in a young adult. Am J Med 1961;30:334-340.

4. Kishore J, Ghoshal U, Ghoshal UC, et al. Infection with cytomegalovirus in patients with inflammatory bowel disease: prevalence, clinical significance and outcome. J Med Microbiol 2004;53(Pt 11):1155-1160.

5. Wada Y, Matsui T, Matake H, et al. Intractable ulcerative colitis caused by cytomegalovirus infection: a prospective study on prevalence, diagnosis, and treatment. Dis Colon Rectum 2003;46(10 Suppl):S59-S65.

6. Domenech E, Vega R, Ojanguren I, et al. Cytomegalovirus infection in ulcerative colitis: a prospective, comparative study on prevalence and diagnostic strategy. Inflamm Bowel Dis 2008;14:1373-1379.

7. Maconi G, Colombo E, Zerbi P, et al. Prevalence, detection rate and outcome of cytomegalovirus infection in ulcerative colitis patients requiring colonic resection. Dig Liver Dis 2005;37:418-423.

8. Cottone M, Pietrosi G, Martorana G, et al. Prevalence of cytomegalovirus infection in severe refractory ulcerative and Crohn's colitis. Am J Gastroenterol 2001;96:773-775.

9. Kambham N, Vij R, Cartwright CA, Longacre T. Cytomegalovirus infection in steroid-refractory ulcerative colitis: a case-control study. Am J Surg Pathol 2004;28:365-373.

10. Kim YS, Kim YH, Kim JS, et al. The prevalence and efficacy of ganciclovir on steroid-refractory ulcerative colitis with cytomegalovirus infection: a prospective multicenter study. J Clin Gastroenterol 2012;46:51-56.

11. Kim JJ, Simpson N, Klipfel N, Debose R, Barr N, Laine L. Cytomegalovirus infection in patients with active inflammatory bowel disease. Dig Dis Sci 2010;55:1059-1065.

12. Knosel T, Schewe C, Petersen N, Dietel M, Petersen I. Prevalence of infectious pathogens in Crohn's disease. Pathol Res Pract 2009;205:223-230.

13. Nakase H, Yoshino T, Honzawa Y, Chiba T. Low prevalence of CMV infection in patients with Crohn's disease 
in comparison with ulcerative colitis: effect of different immune response on prevalence of CMV infection. Dig Dis Sci 2010;55:1498-1499.

14. Pillet S, Pozzetto B, Jarlot C, Paul S, Roblin X. Management of cytomegalovirus infection in inflammatory bowel diseases. Dig Liver Dis 2012;44:541-548.

15. Rahier JF, Magro F, Abreu C, et al. Second European evidence-based consensus on the prevention, diagnosis and management of opportunistic infections in inflammatory bowel disease. J Crohns Colitis 2014;8:443-468.

16. Mun JI, Shin SJ, Yu BH, et al. A case of hemophagocytic syndrome in a patient with fulminant ulcerative colitis superinfected by cytomegalovirus. Korean J Intern Med 2013;28:352-355.

17. Matsumoto S, Yoshida $Y$. What are the factors that affect hospitalization and surgery for aggravation of ulcerative colitis? Eur J Gastroenterol Hepatol 2014;26:282-287.

18. Park SH, Yang SK, Hong SM, et al. Severe disease activity and cytomegalovirus colitis are predictive of a nonresponse to infliximab in patients with ulcerative colitis. Dig Dis Sci 2013;58:3592-3599.

19. Kim YS, Kim YH, Kim JS, et al. Long-term outcomes of cytomegalovirus reactivation in patients with moderate to severe ulcerative colitis: a multicenter study. Gut Liver 2014;8:643-647.

20. Matsuoka K, Iwao Y, Mori T, et al. Cytomegalovirus is frequently reactivated and disappears without antiviral agents in ulcerative colitis patients. Am J Gastroenterol 2007;102:331-337.

21. Yoshino T, Nakase H, Ueno S, et al. Usefulness of quantitative real-time PCR assay for early detection of cytomegalovirus infection in patients with ulcerative colitis refractory to immunosuppressive therapies. Inflamm Bowel Dis 2007;13:1516-1521.

22. do Carmo AM, Santos FM, Ortiz-Agostinho CL, et al. Cytomegalovirus infection in inflammatory bowel disease is not associated with worsening of intestinal inflammatory activity. PLoS One 2014;9:e111574.

23. McCurdy JD, Jones A, Enders FT, et al. A model for identifying cytomegalovirus in patients with inflammatory bowel disease. Clin Gastroenterol Hepatol 2015;13:131-137.

24. Gauss A, Rosenstiel S, Schnitzler P, et al. Intestinal cytomegalovirus infection in patients hospitalized for exacerbation of inflammatory bowel disease: a 10-year tertiary referral center experience. Eur J Gastroenterol Hepatol 2015;27:712-720.
25. Sager K, Alam S, Bond A, Chinnappan L, Probert CS. Review article: cytomegalovirus and inflammatory bowel disease. Aliment Pharmacol Ther 2015;41:725-733.

26. Iida T, Ikeya K, Watanabe F, et al. Looking for endoscopic features of cytomegalovirus colitis: a study of 187 patients with active ulcerative colitis, positive and negative for cytomegalovirus. Inflamm Bowel Dis 2013;19:1156-1163.

27. Suzuki H, Kato J, Kuriyama M, Hiraoka S, Kuwaki K, Yamamoto K. Specific endoscopic features of ulcerative colitis complicated by cytomegalovirus infection. World J Gastroenterol 2010;16:1245-1251.

28. Kim JW, Boo SJ, Ye BD, et al. Clinical utility of cytomegalovirus antigenemia assay and blood cytomegalovirus DNA PCR for cytomegaloviral colitis patients with moderate to severe ulcerative colitis. J Crohns Colitis 2014;8:693-701.

29. Chun J, Lee C, Kwon JE, et al. Usefulness of the cytomegalovirus antigenemia assay in patients with ulcerative colitis. Intest Res 2015;13:50-59.

30. Chang $\mathrm{S}$, Cheon JH. A clinical significance of assessing cytomegalovirus infection status in patients with ulcerative colitis. Intest Res 2015;13:2-3.

31. Kandiel A, Lashner B. Cytomegalovirus colitis complicating inflammatory bowel disease. Am J Gastroenterol 2006;101:2857-2865.

32. Beaugerie L, Cywiner-Golenzer C, Monfort L, et al. Definition and diagnosis of cytomegalovirus colitis in patients infected by human immunodeficiency virus. J Acquir Immune Defic Syndr Hum Retrovirol 1997;14:423429.

33. McCoy MH, Post K, Sen JD, et al. qPCR increases sensitivity to detect cytomegalovirus in formalin-fixed, paraffin-embedded tissue of gastrointestinal biopsies. Hum Pathol 2014;45:48-53.

34. Cotte L, Drouet E, Bissuel F, Denoyel GA, Trepo C. Diagnostic value of amplification of human cytomegalovirus DNA from gastrointestinal biopsies from human immunodeficiency virus-infected patients. J Clin Microbiol 1993;31:2066-2069.

35. Roblin X, Pillet S, Oussalah A, et al. Cytomegalovirus load in inflamed intestinal tissue is predictive of resistance to immunosuppressive therapy in ulcerative colitis. Am J Gastroenterol 2011;106:2001-2008.

36. Ciccocioppo R, Racca F, Paolucci S, et al. Human cytomegalovirus and Epstein-Barr virus infection in inflammatory bowel disease: need for mucosal viral load mea- 
surement. World J Gastroenterol 2015;21:1915-1926.

37. Zidar N, Ferkolj I, Tepes K, et al. Diagnosing cytomegalovirus in patients with inflammatory bowel disease: by immunohistochemistry or polymerase chain reaction? Virchows Arch 2015;466:533-539.

38. McCurdy JD, Enders FT, Jones A, et al. Detection of cytomegalovirus in patients with inflammatory bowel disease: where to biopsy and how many biopsies? Inflamm Bowel Dis 2015;21:2833-2838.

39. de la Hoz RE, Stephens G, Sherlock C. Diagnosis and treatment approaches of CMV infections in adult patients. J Clin Virol 2002;25 Suppl 2:S1-S12.

40. Landry ML, Ferguson D. Comparison of quantitative cytomegalovirus antigenemia assay with culture methods and correlation with clinical disease. J Clin Microbiol 1993;31:2851-2856.

41. Kornbluth A, Sachar DB; Practice Parameters Committee of the American College of Gastroenterology. Ulcerative colitis practice guidelines in adults: American College Of Gastroenterology, Practice Parameters Committee. Am J Gastroenterol 2010;105:501-523.

42. Choi CH, Moon W, Kim YS, et al. Second Korean guideline for the management of ulcerative colitis. Korean J Gastroenterol 2017;69:1-28.

43. Maconi G, Lombardini M, Furfaro F, Bezzio C, Zerbi P, Ardizzone S. Long-term outcome of inflammatory bowel diseases with cytomegalovirus colitis: effect of antiviral treatment. Eur J Gastroenterol Hepatol 2014;26:1146-1151.

44. Shukla T, Singh S, Loftus EV Jr, Bruining DH, McCurdy JD. Antiviral therapy in steroid-refractory ulcerative colitis with cytomegalovirus: systematic review and meta-analysis. Inflamm Bowel Dis 2015;21:2718-2725.

45. Jones A, McCurdy JD, Loftus EV Jr, et al. Effects of antiviral therapy for patients with inflammatory bowel disease and a positive intestinal biopsy for cytomegalovirus. Clin Gastroenterol Hepatol 2015;13:949-955.

46. Omiya M, Matsushita M, Tanaka T, Kawamata S, Okazaki
$\mathrm{K}$. The absence of large ulcer predicts latent cytomegalovirus infection in ulcerative colitis with positive mucosal viral assay. Intern Med 2010;49:2277-2282.

47. Pillet S, Pozzetto B, Roblin X. Cytomegalovirus and ulcerative colitis: place of antiviral therapy. World J Gastroenterol 2016;22:2030-2045.

48. Criscuoli V, Casa A, Orlando A, et al. Severe acute colitis associated with CMV: a prevalence study. Dig Liver Dis 2004;36:818-820.

49. Papadakis KA, Tung JK, Binder SW, et al. Outcome of cytomegalovirus infections in patients with inflammatory bowel disease. Am J Gastroenterol 2001;96:2137-2142.

50. Czock D, Scholle C, Rasche FM, Schaarschmidt D, Keller F. Pharmacokinetics of valganciclovir and ganciclovir in renal impairment. Clin Pharmacol Ther 2002;72:142-150.

51. Einsele H, Ehninger G, Steidle M, et al. Polymerase chain reaction to evaluate antiviral therapy for cytomegalovirus disease. Lancet 1991;338:1170-1172.

52. Ciccocioppo R. Letter: cytomegalovirus infection in inflammatory bowel disease. Aliment Pharmacol Ther 2015;42:127-129.

53. Landsman MJ, Sultan M, Stevens M, Charabaty A, Mattar MC. Diagnosis and management of common gastrointestinal tract infectious diseases in ulcerative colitis and Crohn's disease patients. Inflamm Bowel Dis 2014;20:2503-2510.

54. D'Ovidio V, Vernia P, Gentile G, et al. Cytomegalovirus infection in inflammatory bowel disease patients undergoing anti-TNFalpha therapy. J Clin Virol 2008;43:180-183.

55. Lavagna A, Bergallo $M$, Daperno $M$, et al. Infliximab and the risk of latent viruses reactivation in active Crohn's disease. Inflamm Bowel Dis 2007;13:896-902.

56. Pillet $\mathrm{S}$, Jarlot $\mathrm{C}$, Courault $\mathrm{M}$, et al. Infliximab does not worsen outcomes during flare-ups associated with cytomegalovirus infection in patients with ulcerative colitis. Inflamm Bowel Dis 2015;21:1580-1586. 